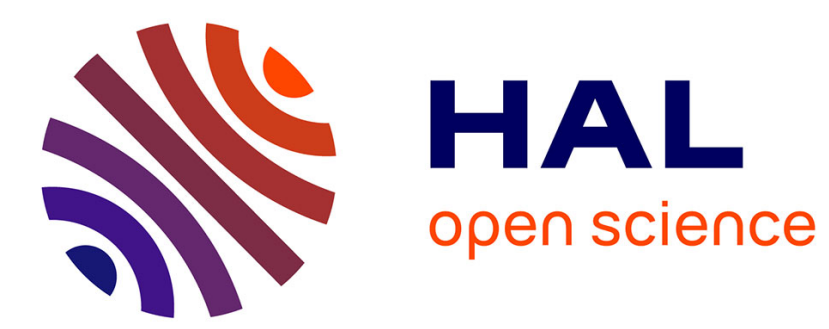

\title{
DEVELOPMENT OF INTERNALLY STRENGTHENED PREREACTED Nb3Sn SUPERCONDUCTORS
}

P. Turowski, A. Nyilas, M. Thöner, P. Sanger

\section{- To cite this version:}

P. Turowski, A. Nyilas, M. Thöner, P. Sanger. DEVELOPMENT OF INTERNALLY STRENGTHENED PREREACTED Nb3Sn SUPERCONDUCTORS. Journal de Physique Colloques, 1984, 45 (C1), pp.C1-399-C1-402. 10.1051/jphyscol:1984181 . jpa-00223737

\section{HAL Id: jpa-00223737 https://hal.science/jpa-00223737}

Submitted on 1 Jan 1984

HAL is a multi-disciplinary open access archive for the deposit and dissemination of scientific research documents, whether they are published or not. The documents may come from teaching and research institutions in France or abroad, or from public or private research centers.
L'archive ouverte pluridisciplinaire HAL, est destinée au dépôt et à la diffusion de documents scientifiques de niveau recherche, publiés ou non, émanant des établissements d'enseignement et de recherche français ou étrangers, des laboratoires publics ou privés. 


\title{
DEVELOPMENT OF INTERNALLY STRENGTHENED PREREACTED $\mathrm{Nb}_{3} \mathrm{Sn}$ SUPERCONDUCTORS
}

\author{
P. Turowski, A. Nyilas, M. Thöner and P.A. Sanger \\ Kemforschungszemtrum Karlsmhe, Institut für Technische Physik, P.0.B. 3640, \\ D-7500 Karlsruhe, F.R.G. \\ "Oxford-AIRCO Superconductors, 600 Milik Street, Carteret, N.J. 07008, U.S.A.
}

\begin{abstract}
Résumé - Les critères d'élaboration pour des conducteurs de $\mathrm{Nb}_{3} \mathrm{Sn}$ préréagis et avec renforcement interne, ainsi que les propriétés supraconductrices à haut champ de conducteurs avec différents matériaux de renforcement sont présentés.
\end{abstract}

Abstract - Design criteria for a prereacted, internally strengthened $\mathrm{Nb}_{3} \mathrm{Sn}$ conductor and the superconducting properties in high fields of conductors with different reinforcing core materials are presented.

\section{INTRODUCTION}

A $10 \mathrm{~T}-1.3 \mathrm{~K}$ superconducting solenoid with a clear bore of $390 \mathrm{~mm}$ is to be rated up in magnetic field by at least 2 'Tesla by means of a $\mathrm{Nb}_{3}$ Sn-insert coil. A reasonable operational current density of $6.5 \cdot 10^{3} \mathrm{~A} / \mathrm{cm}^{2}$ in the conductor leads to the following size of the insert coil: $300 \mathrm{~mm}$ i. dia., $380 \mathrm{~mm} \mathrm{o}$. dia. and a length of $400 \mathrm{~mm}$. A prereacted $\mathrm{Nb}_{3} \mathrm{Sn}$ conductor must be used in the windings for forming cooling channels to warrant a sufficient electrical stability by LHerventilation. The Lorentz forces of $150 \mathrm{~N} / \mathrm{mm}^{-2}$ in the coil require a mechanical reinforcement of the conductor. A compacted monolith configuration with a central steel core seemed to be a reasonable solution. 1),2)

\section{THE CONDUCTOR CONFIGURATION}

The geometric size of a prereacted $\mathrm{Nb}_{3} \mathrm{Sn}$ conductor is not only determined by the operational current, but the thickness of the conductor is determined by the strain occurring by bending during the winding of a coil. The $\mathrm{Nb}_{3} \mathrm{Sn}$ conductor will be damaged irreversibly at strains exceeding $0,6 \%$, as shown by kuckuck et al ${ }^{3}$ ) and Rupp ${ }^{4}$ ). The tensionless state of a long length of such a conductor is a bent one, because the heat treatment has to be made on a spoo1. From this state, the conductor will be straightened and rebent again and experiences strain and compression during the processing, so that the final geometric size is a compromise regarding all the steps of handling. Thus, for a final bending diameter of $300 \mathrm{~mm}$ and a heat treatment diameter of $600 \mathrm{~mm}$, a conductor thickness of $3.5 \mathrm{~mm}$ seemed to be tolerable, in particular un-

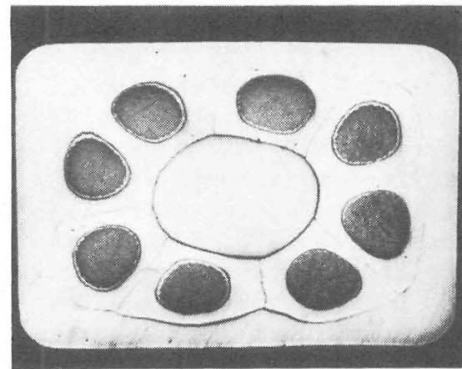

Fig. 1 (a)

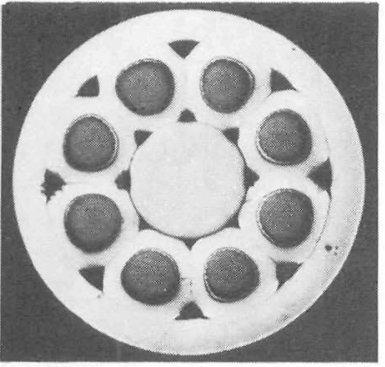

Fig. 1 (b) der the aspect that the distance of the $\mathrm{Nb}_{3} \mathrm{Sn} \mathrm{fiI}-$ aments from the neutral axis is smaller than 1.75 $\mathrm{mm}$, which can be seen in Fig. 1 (a). The final. strain $\varepsilon$ between heat

Fig. 1:

The final size of the conductor (a);

the conductor in the first stage of compaction (b). 
treatment radius $r_{I}$ and coil radius $r_{2}$ corresponds to the formula $\varepsilon=a\left[1 / r_{2}-1 / r_{1}\right]$ with the distance $a$ between outermost filaments and the neutral axis. For the present conductor the expected strain value will be $0.46 \%$.

Fig. 1 (a,b) show a cross section through the final compacted monolith of $3.5 \times 5$ $\mathrm{mm}^{2}$ and a slightly compacted version after the encapsulation into the outer copper sleeve. The strands contain $64 \%$ copper and are protected by a Ta-diffusion barrier. Because the strengthening material experiences also the heat treatment of the $\mathrm{Nb}_{3} \mathrm{Sn}$, it must be a creep resistant material to keep sufficiently high yield strength. In the prototype conductors steel A 206, inconel, a molybdenum alloy, IZl, and from reason of comparison copper were used as core materials. They differ considerably in the thermal contraction coefficient $\alpha\left[{ }^{\circ} \mathrm{C}^{-1}\right]$ e.g. at room temperature $17.8 \cdot 10^{-6}$ for A $236,14.9 \cdot 10^{-6}$ for inconel, $4.9 \cdot 10^{-6}$ for TZl and $16.7 \cdot 10^{-6}$ for copper. The steel A 286 was favoured, because the hardening heat treatment could be made in combination with the $\mathrm{Nb}_{3} \mathrm{Sn}$ heat treatment. The other core materials werc included in the investigations to study the influence of the different thermal contraction on the current density.

The composite conductor should fulfil the following requirements:

$$
\begin{array}{ll}
\text { Cross section } & \mathrm{q}=3.5 \mathrm{x} \mathrm{mm} \\
\text { Critical current } & \mathrm{I}_{\mathrm{c}}=1750 \mathrm{~A}(0.5 \mu \mathrm{V} / \mathrm{cm} \text { at } 10 \mathrm{~T} \text { and } \mathrm{T}=4.2 \mathrm{~K}) \\
\text { Yield strength } & \sigma_{0.1}=150 \mathrm{~N} / \mathrm{mm}^{2} \\
\text { Cu/non-copper ratio } & \text { Cu/bronze }>3 \\
\text { Twist in strand } & 50 \mathrm{~mm} \\
\text { Transposition in cable } 100 \mathrm{~mm}
\end{array}
$$

From empirical data of current density, a content of $20 \% \mathrm{Nb}_{3} \mathrm{Sn} ;$ bronze in the cross section should be sufficient. A subdivision of the remaining area into a copper and a steel part can only be made very crudely by simplifying assumptions. The mixing rule, assuming steel to behave elastically, copper and bronze being in the plastic regime and contributing to force carrying by $30 \mathrm{~N} / \mathrm{mm}^{2}$ and $150 \mathrm{~N} / \mathrm{mm}^{2}$ respectively, zives a steel fraction of $12 \%$. The composition of $20 \% \mathrm{Nb}_{3}$ Sn-bronze, $58 \%$ copper and $12 \%$ core material could not be achieved in all the samples because all the core materials were not available in the right dimensions.

\section{CRITICAL CURREIT VALUES}

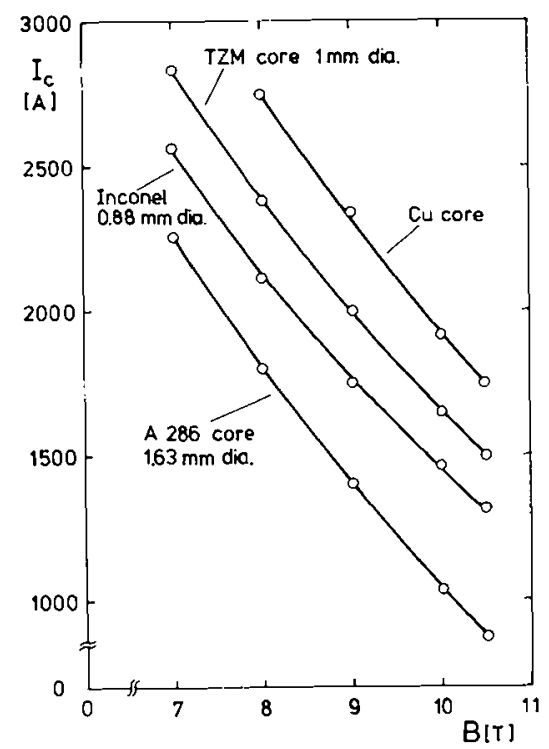

Fig. 2:

The critical currents $I_{c}$ versus magnetic field $\mathrm{B}$ of the $\mathrm{Nb}_{3} \mathrm{Sn}$ conductor with different core materials.
The critical. currents were measured in one layer "wind and react" coil sample over one turn at least, i.e. $29 \mathrm{~cm}$, whereas the total number of turns was four. The $I_{c}$ values were defined for a voltage drop of $0.5 \mu \mathrm{V} / \mathrm{cm}$ and determined up to fields of $10.5 \mathrm{~T}$. Because the bare conductor was well cooled by the liquid helium environment, the conductor was tested far into the current sharing regime where heat fluxes up to $7 \cdot 10^{-2}$ Watts $/ \mathrm{cm}^{2}$ occurred.

Fig. 2 shows the critical current values for the $\mathrm{Nb}_{3} \mathrm{Sn}$ conductors with the different strengthening cores. The conductor with the copper core can serve as the basis for comparison, because the composition of $\mathrm{Nb}_{3} \mathrm{Sn}$, CuSn-bronze and copper corresponds to the usual arrangement in multifilamentary $\mathrm{Nb}_{3} \mathrm{Sn}$ conductors. Obviously the current densities decrease with increasing thermal contraction coefficient of core material as was expected.5),6) Also in the slightly compacted state the compacted cable showed the same reduction in $I_{c}$ as in case of $100 \%$ compaction comparing e.g. the A 286 core conductor with the copper core conductor. The current sharing regime in these $\mathrm{Nb}_{3} \mathrm{Sn}$ conductors is very much extended and covers between a voltage drop of $0.5 \mu \mathrm{V} / \mathrm{cm}$ to $33 \mu \mathrm{V} / \mathrm{cm}$ an increase of current of about $700 \mathrm{~A}$. The copper matrix contributes only about $70 \mathrm{~A}$ to the current carrying capacity. Some typical data in 


\begin{tabular}{|c|c|c|c|c|c|c|}
\hline $\begin{array}{l}\text { Tab. I: The critical current } \\
\mathrm{I}_{\mathrm{c}} \text {, current } \mathrm{I}_{\mathrm{cs}} \text { in the cur- } \\
\text { rent sharing regime, } \mathrm{I}_{\mathrm{Cu}} \\
\text { the current in the copper }\end{array}$ & Core & $\begin{array}{l}\mathrm{I}_{\mathrm{c}}[\mathrm{A}] \\
0.5 \mu \mathrm{V} / \\
\mathrm{cm}\end{array}$ & $\begin{array}{l}\rho_{\mathrm{c}} \\
{[\Omega \mathrm{cm}]}\end{array}$ & $\begin{array}{l}I_{\mathrm{cs}}[\mathrm{A}] \\
33 \mu \mathrm{V} / \mathrm{cm}\end{array}$ & $\begin{array}{l}\mathrm{I}_{\mathrm{Cu}} \\
{[\mathrm{A}]}\end{array}$ & $\begin{array}{l}\rho_{\mathrm{Cs}} \\
{[\Omega \mathrm{cm}]}\end{array}$ \\
\hline $\begin{array}{l}\text { natrix and the corresponding } \\
\text { resistivity } \rho \text { in the } \mathrm{Nb}_{3} \mathrm{Sn} / \\
\text { bronze cross section at } \\
10.5 \mathrm{~T} \text {. }\end{array}$ & $\begin{array}{l}\mathrm{Cu} \\
\mathrm{TZM} \\
\text { Incone } 1 \\
\text { A } 236\end{array}$ & $\begin{array}{r}1750 \\
1500 \\
1317 \\
375\end{array}$ & $\begin{array}{l}9.5 \cdot 10^{-12} \\
1.11 \cdot 10^{-11} \\
1.26 \cdot 10^{-11} \\
1.9 \cdot 10^{-11}\end{array}$ & $\begin{array}{l}2465 \\
2233 \\
2000 \\
1542\end{array}$ & $\begin{array}{l}32.5 \\
77.5 \\
77.5 \\
70.4\end{array}$ & $\begin{array}{l}4.66 \cdot 10^{-10} \\
5.14 \cdot 10^{-10} \\
5.76 \cdot 10^{-10} \\
7.0 \cdot 10^{-10}\end{array}$ \\
\hline
\end{tabular}

the current sharing regime are compiled in Tab. I. The extended current sharing regime indicates that the $\mathrm{Nb}_{3} \mathrm{Sn}$ in this conductor can be operated steadily beyond the critical current value in a relatively high resistive state. The logarithmic increment $\alpha$ of the increase of resistivity with transport current $\left(\rho=\rho_{0} \exp \left[\alpha \cdot\left(I-I_{0}\right)\right]\right)$ has the same value $6.04 \cdot 10^{-3}\left[\mathrm{~A}^{-1}\right]$ for all the configurations. In comparing the critical current of strain influenced conductors it might be more convenient to use an $I_{c}$ definition on the base of the resistivity of the superconductor in the non-copper cross section instead of a voltage/cm-definition, because that is likewise correlated to an internal physical property. Thus, a resistivity value of $\rho=10^{-11} \Omega \mathrm{cm}$ of the superconductor in the bronze cross section, a value sometimes used, would leave unchanged the $I_{c}$ value in the case of the copper core but decrease the $I_{c}$ value from $875 \mathrm{~A}$ down to $770 \mathrm{~A}$ in case of the A 236 core.

\section{THE CURRENT SHARIIIG STATE IN DEPENDENCE ON MAGNETIC FIELDS}

The high field part of the coil could be run in the current sharing state if the available cooling power would be sufficient. An estimation of the losses to be expected needs the knowledge of current sharing behaviour in dependence on the magnetic field. Heasurements of the current sharing voltage at constant current in a decreasing magnetic field give in a first approximation an exponential relationship for the resistivity $\rho=0_{0} \exp \left[-\gamma \cdot\left(B_{0}-B\right)\right]$ with a logarithmic decrement $\gamma=1.93$. From that, a mean resistivity for the total coil can be derived taking into account the field change over the coil.

$$
\bar{\rho}=\frac{\rho_{0}}{\Delta B_{r} \cdot \Delta B_{z}} \int_{0}^{\Delta B_{r}} \int_{0}^{\Delta B_{2}} \exp \left[-\gamma\left(B_{r}+B_{z}\right)\right] d B_{r} d B_{z}
$$

The losses of the insert coil mentioned before would be 3.6 Watts if it operates at a voltage of $0.5 \mu \mathrm{V} / \mathrm{cm}$ and a current level of $1350 \mathrm{~A}$, i.e. at critical current, in the high field windings. This demonstrates that the current sharing regime cannot be used in a steady operation mode.

\section{TRIAL WINDINGS}

About $5 \mathrm{~m}$ of different conductor samples were heat treated on a $600 \mathrm{~mm}$ diameter spool at $700^{\circ} \mathrm{C}$ for $120 \mathrm{~h}$ and from that wound onto a sample coil of $300 \mathrm{~mm}$. The four windings were wound cight to the bore tube and insulated from turn to turn by a capton foil. The outer side of the conductor was wetted by liquid helium.

The investigations were performed in the $390 \mathrm{~mm}$ bore of the magnet mentioned before at $4.2 \mathrm{~K}$ up to $\& \mathrm{~T}$. The Lorentz forces cause tensile or compressive forces on the conductor depending on the direction of sample current $(\sigma= \pm j \cdot B \cdot r)$. The compressive forces in particular are supported by the bore tube so that the conductor has to carry no forces. First the critical current values of the conductors were determined in the force free mode and then under tensile forces. Pure bending caused a reduction in critical current between 10 and $15 \%$ compared to values gained from the "wind and react" samples. This must be deduced from the tensile and compressive forces occurring in the curved conductor which do not compensate due to the non-1inearity of the stress eifects. ${ }^{6}$ Even in twisted and transposed conductors there is no balance by bypass currents because of the resistivity of the matrix. In any case, bending will lead to a certain reduction in critical current.

The effects of bending and tensile load on the conductor are given in Tab. II for the inconel and $T Z M$ core, where $I_{C}, I_{c b}$ and $I_{c} *$ are the critical currents in the short sample, in the curved conductor and under tensile load, and $\sigma^{*}$ the tensile force at $8 \mathrm{~T}$ and $\mathrm{I}_{\mathrm{C}}$. 
Tab. IJ:

The critical currents of: different conductor configurations at different stages of load at $8 \mathrm{~T}$.

\begin{tabular}{|l|l|l|l|l|}
\hline Core & $I_{c}[A]$ & $I_{c b}[A]$ & $I_{c}{ }^{*}[A]$ & $\sigma^{*}\left[\mathrm{~N} / \mathrm{mm}^{2}\right]$ \\
\hline $\begin{array}{l}\text { Inconel } \\
\text { TZM }\end{array}$ & 2117 & 1367 & 2050 & 141 \\
\hline
\end{tabular}

The Tab. II reveals that the core materials inconel and TZM have a different effect on the current densities of $\mathrm{Nb}_{3} \mathrm{Sn}$ under force load. Under the bending tension both conductor configurations experience a reduction in current density, the TZM configuration a little bit more than the inconel version. Under tensile forces the current density of the inconel version increases whereas that of the TZM version decreases. At the test the maximum load by running into the current sharing regime was 166 $\mathrm{N} / \mathrm{mm}^{2}$ with inconel and $137 \mathrm{~N} / \mathrm{mm}^{2}$ with TZM. These maximum loads were cycled five, times and by that the TZM version cxhibited an aging effect in the sense that from the first run to the fifth the $I_{c} *$ value dropped from $1300 \Lambda$ to $1675 \Lambda$ with a tendency of approaching a constant value. The conductors were stressed up to the plastic regime and a remaining strain of about $0.2 \%$ could be measured by the change of conductor length. The behaviour of the TZM core conductor suggests a reduction of precompression effect by the small. thermal contraction of molybdenum so that the original state is near the maximum value in the $I_{C} / \varepsilon$ characteristic and the tensile forces lead very soon into the decreasing branch, as was verified by measurements of Specking et al. ${ }^{7}$;

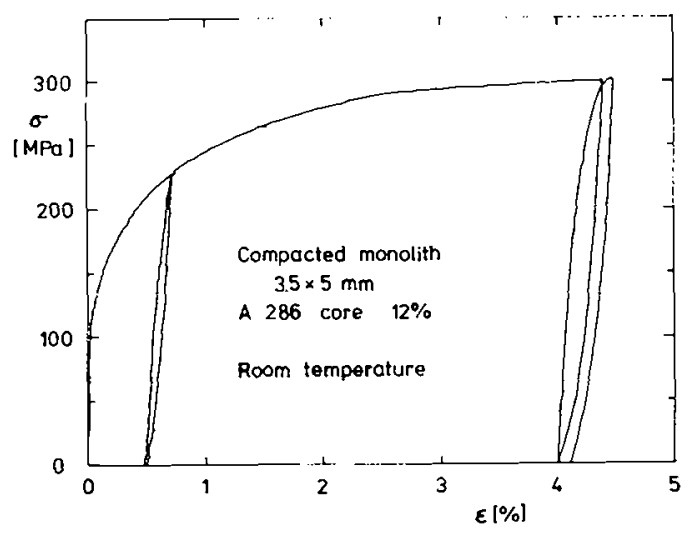
$\Lambda$ rewinding of the $5 \mathrm{~m}$ length of the in conel core conductor showed an enhancement of $I_{c}^{*}$ up to $2133 \mathrm{~A}$. That might be an effect of the plastic deformation reducing the precompression. A stressstrain characteristic of the A 286 core conductor is given in Fig. 3. The high content of copper and copper-tin bronze being in a weak state after the heat treatment leads to the very early indication of plastic behaviour at $\varepsilon \geqslant 0.1 \%$. At a virgin elongation of $0.3 \%$ the conductor obtained a remaining elongation of $0.1 \%$. The stress strain behaviour at room temperature can be considered as representative also for LHe-temperature because the enhancement in yield strength and average modulus of elasticity at low temperature is negligible

Fig. 3: Stress-strain characteristic from a practical point of view.

\section{CONCLUSION}

The investigations have shown that strenghening considerably influences the critical current density of $\mathrm{Nb}_{3} \mathrm{Sn}$ conductors, due to its differential thermal contraction coefficient. The results of the inconel respectively the $A 286$ core and of the TZM core suggest the possibility of compensating the thermal contraction effects by selected core materials. In the range of bending strain up to $0.6 \%$ the prereacted conductor can be wound and rewound without any damage. The final bending strain should be small to keep the loss in critical current in a tolerable limit of $10 \%$.

\section{REFE RENCES}

1) Spencer, C.R., Adam, E., Gregory, E., Adv. Cryog. Eng. 28, p. 815 (1982).

2) Spencer, C.R. et al., Proc. 8th Symp. Eng. Prob. Fusion Res. 1979, p. 265.

3) Kuckuck, H., Springer, E., Ziegler, G., Cryogenics 16, 350 (1976).

4) Rupp, G., J. App1. Phys. 48, 3858 (1977).

5) Flükiger, R., Drost, E., Goldacker, W., Specking, W., IEEE Trans. Mag., MAG-19, 1441 (1983).

6) Ekin, J.W., Cryogenics 20,611 (1980).

7) Specking, W, Flïkiger, $\bar{R}$, to be presented at MT-8, to be pub1. in Journal de Phys. 